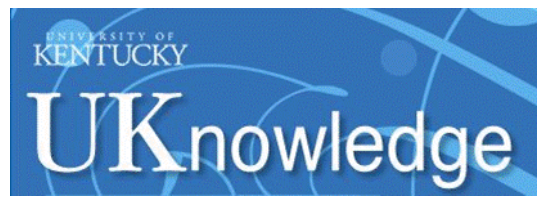

University of Kentucky

UKnowledge

$4-1-2020$

\title{
Evaluating the Effects of Electric and Magnetic Loading on the Performance of Single and Double Rotor Axial Flux PM Machines
}

\author{
Narges Taran \\ University of Kentucky, narges.taran@uky.edu \\ Greg Heins \\ Regal Beloit Corporation, Australia \\ Vandana Rallabandi \\ University of Kentucky, vandana.rallabandi@uky.edu \\ Dean Patterson \\ Regal Beloit Corporation, Australia \\ Dan M. Ionel \\ University of Kentucky, dan.ionel@uky.edu
}

Follow this and additional works at: https://uknowledge.uky.edu/peik_facpub

Part of the Electromagnetics and Photonics Commons, and the Power and Energy Commons

Right click to open a feedback form in a new tab to let us know how this document benefits you.

\section{Repository Citation}

Taran, Narges; Heins, Greg; Rallabandi, Vandana; Patterson, Dean; and Ionel, Dan M., "Evaluating the Effects of Electric and Magnetic Loading on the Performance of Single and Double Rotor Axial Flux PM Machines" (2020). Power and Energy Institute of Kentucky Faculty Publications. 5.

https://uknowledge.uky.edu/peik_facpub/5

This Article is brought to you for free and open access by the Power and Energy Institute of Kentucky at UKnowledge. It has been accepted for inclusion in Power and Energy Institute of Kentucky Faculty Publications by an authorized administrator of UKnowledge. For more information, please contact UKnowledge@lsv.uky.edu. 


\title{
Evaluating the Effects of Electric and Magnetic Loading on the Performance of Single and Double Rotor Axial Flux PM Machines
}

\author{
Digital Object Identifier (DOI) \\ https://doi.org/10.1109/TIA.2020.2983632
}

\section{Notes/Citation Information}

Published in IEEE Transactions on Industry Applications.

(C) 2020 IEEE Copyright Notice. "Personal use of this material is permitted. Permission from IEEE must be obtained for all other uses, in any current or future media, including reprinting/republishing this material for advertising or promotional purposes, creating new collective works, for resale or redistribution to servers or lists, or reuse of any copyrighted component of this work in other works.

The document available for download is the authors' manuscript version that is accepted for publication. The final published version is copyrighted by IEEE and will be available as: N. Taran, G. Heins, V.

Rallabandi, D. Patterson, andD. M. Ionel, "Evaluating the Effects of Electric and Magnetic Loading on the Performance of Single and Double Rotor Axial Flux PM Machines," IEEE Transactions on Industry Applications, 2020, 10 p. 


\title{
Evaluating the Effects of Electric and Magnetic Loading on the Performance of Single and Double Rotor Axial Flux PM Machines
}

\author{
Narges Taran, Member, IEEE, Greg Heins, Member, IEEE, Vandana Rallabandi, Senior Member, IEEE, \\ Dean Patterson, Life Fellow, IEEE, Dan M. Ionel, Fellow, IEEE
}

\begin{abstract}
Axial flux PM (AFPM) machines are used particularly in applications requiring a compact structure. Their disc shape topology and axial air-gap have led to a variety of configurations including two popular ones: the yokeless and segmented armature (YASA), and the single-stator singlerotor or single sided machine. In this study, a comprehensive comparative analysis of these configurations is conducted at different magnetic and electric loadings. It is found that at lower loadings, typically employed for air-cooled machines, the torque/ampere characteristics of the YASA machine are almost identical to those of a single sided machine constructed with half the magnet volume. On the other hand, the single sided machine outperforms the YASA machine when the magnet volumes in both machines are maintained equal. However, for higher electric loadings, the torque/ampere characteristics of the YASA machine droop significantly less than those of the single sided machine. The paper includes analytical estimations which are verified with experimentally validated FEA simulations. In addition, the impacts of the armature reaction on saturation and the magnetic flux linkage, the magnet losses and eddy current losses in both machines are also explored.
\end{abstract}

Index Terms-Axial flux permanent magnet, yokeless and segmented armature, YASA, armature reaction, power factor, eddy current losses, magnet losses, torque production.

\section{INTRODUCTION}

Axial flux permanent magnet (AFPM) machines are acclaimed for their high efficiency, torque density, and compact structure. The disc shape topology has opened up many possibilities for variants, where their counterparts in the radial air-gap form involve a high degree of mechanical complexity [1]. One such variant is the double outside rotor machine with a yokeless and segmented armature (YASA) between the rotors [2], [3]. This configuration can be viewed as an axially mirrored and duplicated version of a single sided AFPM machine without the stator yoke.

YASA machines exploit and apply the benefits of fractional slot concentrated windings to the TORUS-NS machine [3], [4],

N. Taran and V. Rallabandi were with the SPARK Laboratory Department of Electrical and Computer Engineering, University of Kentucky, Lexington, KY 40506 USA and they are now with BorgWarner Inc., Noblesville Technical Center, IN and with GE Research, Niskayuna, NY, respectively (e-mails: narges.taran@ieee.org and vandana.rallabandi@ieee.org).

D. M. Ionel is with the SPARK Laboratory, Department of Electrical and Computer Engineering, University of Kentucky, Lexington, KY 40506 USA (e-mail: dan.ionel@ieee.org).

G. Heins and D. Patterson are with the Regal Beloit Corporation, Australia, Rowville, VIC 3178, Australia (e-mails: greg.heins@ regalbeloit.com; dean.patterson@regalbeloit.com). which was originally conceived and studied with a distributed winding. The yokeless structure opens up the possibility of employing grain oriented steel in the segmented stator structure. The fractional slot concentrated winding facilitates the modular stator teeth construction which results in a higher fill factor, reduced mutual inductance between phases (thereby improving the phase independency and fault tolerance), a higher efficiency, and compactness [5].

The mechanical challenges of the YASA topology remain its major drawbacks and are twofold. Firstly, if the segmented stator sections are to be made of laminated steel and stacked radially, they should increase in circumferential width from the inner to the outer radius. That is, to carry the axially directed flux, each single lamination must be differently shaped. This can be addressed by methods such as punching reduced width laminations, or using soft magnetic composite (SMC) materials [5]-[7]. The second drawback is the difficulty of holding the individual stator segments in place while maintaining a balanced air-gap [8]. This can be resolved by utilizing annular plates containing openings the same size as the shoe of the stator segments [7], or by incorporating ring holders [5]. The YASA structure also adds to thermal challenges due to the windings located deep between the two rotor discs, causing reduced heat dissipation [9].

The design procedure of the YASA machine topoogy has been presented, for example in [2], [3], [10]. A comparative study conducted on transverse flux, radial flux, and YASA machines with identical dimensions and the same PM mass concluded that the transverse flux topology performs better when a low speed, a high torque, and small electric loadings are desired. However, in case of limited axial lengths, YASA is found to be superior [11]. In another study, YASA, single sided, and TORUS machines were compared [12], showing that the torque density $\left(\mathrm{Nm} / \mathrm{m}^{3}\right)$ of YASA is higher than the others at the rated specifications of an electric vehicle. Another paper compares single sided, double sided, and a novel Eshaped core AFPM machine with either opposing or similar poles facing each other, and concludes that while the double sided machine has higher torque density, the single sided one can achieve a wider speed range [13]. A comparison between magnetically geared and conventional YASA machines, has shown that the magnetically geared topology can produce higher torque [14]. The application of two different soft magnet composite (SMC) materials in the stator core of a YASA

Authors' manuscript accepted for publication. The final published version is copyrighted by IEEE and will be available as: N. Taran, G. Heins, V. Rallabandi, D. Patterson, and D. M. Ionel, "Evaluating the Effects of Electric and Magnetic Loading on the Performance of Single and Double Rotor Axial Flux PM Machines," IEEE Transactions on Industry Applications, 2020, 10p. (C)2020 IEEE Copyright Notice. "Personal use of this material is permitted. Permission from IEEE must be obtained for all other uses, in any current or future media, including reprinting/republishing this material for advertising or promotional purposes, creating new collective works, for resale or redistribution to servers or lists, or reuse of any copyrighted component of this work in other works." 


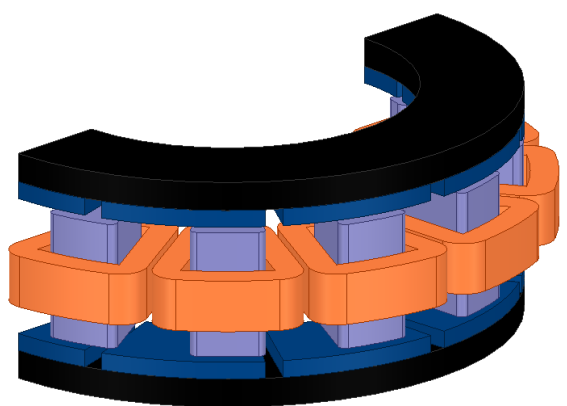

(a)

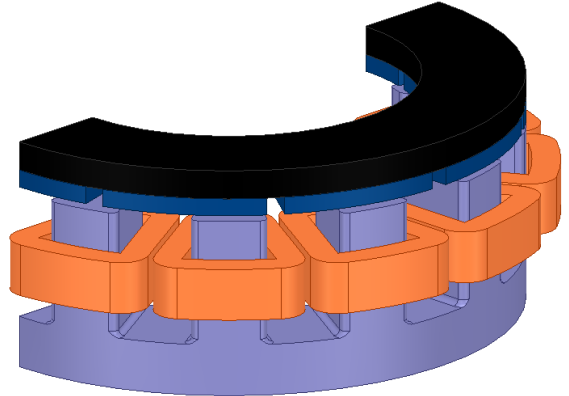

(b)

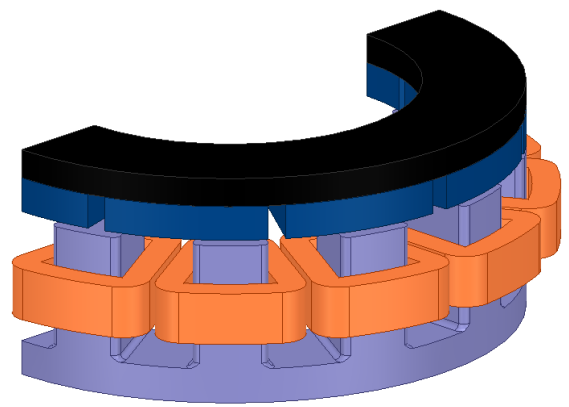

(c)

Fig. 1. The 3D FEA parametric model of three topologies to be studied; (a) the YASA structure, (b) the single sided machine with half the total magnet volume as the YASA (S1M), and (c) the single sided machine with the same total magnet volume as the YASA (S2M).

machine was presented in [15]. The use of an SMC material in rotor back iron was tested in another study, concluding that the SMC rotor can contribute to an increased efficiency, while back iron saturation causes some level of saliency [16]. A comparative analysis between surface mounted and spoke type AFPM machines has indicated that while the latter achieves wider speed range and is more economical from PM cost perspective, it is more challenging to fabricate [17]. The AFPM machines with integral and fractional slot windings were compared in another paper, showing that with similar electric and magnetic loading the integral winding yields greater torque and lower losses while the torque ripple is higher [18].

The literature lacks a comprehensive comparative study across a wide range of loadings. This paper aims to fill this gap and is an expanded follow-up to a previous conference paper by the same authors [19]. The torque constant, power factor, and overload capability of the YASA and single sided machines designed within the same physical envelope are compared.

The paper is structured as follows: the specifications of the machine topologies under comparison are explain in the next section, which also includes a discussion on the cooling requirements for these machines. Analytical estimation of the torque production capability and its dependency on the electric and magnetic loadings is discussed in section III. Section IV is dedicated to the sensitivity analysis. The performance of the machines under typical loadings is discussed in Section V. The overload capability and experimental results are presented in detail in section VI and VII. The last section summarizes the outcomes of this study.

\section{Specifications of the Topologies Compared}

The comparative study is conducted between three topologies: 1) a YASA structure, 2) a single sided machine with half the total magnet volume of the YASA machine (S1M), and 3) a single sided machine with the same total magnet volume as the YASA structure (S2M). The parametric models are presented in Fig. 1. They all have 10 poles and 12 open slots. The axial length, active diameter, slot depths and copper volume are maintained constant for all three machines. The rotor back iron lengths are identical while the stator yoke thickness is adjusted based on mechanical limitations and a constrained total axial length. The stator employs SMC in all cases.

Most of the geometrical specifications were kept unchanged throughout the current study, in order to provide engineering insights on whether the difference in performance can be attributed, in principle, to the design configuration itself, i.e. YASA or single-sided layout. The sensitivity analysis described in the next section, identifies the influences of potential design variations on output performance. Another systematic approach, in which machines of different topologies were designed through formal mathematical optimization, has been reported by the group of authors in another paper [20].

Comparative studies with both ferrite (remanence of $0.4 \mathrm{~T}$ ) and rare earth magnets (remanence of $1.23 \mathrm{~T}$ ) are conducted in order to reach a general conclusion within a wide range of magnetic loading. All analyses are performed with 3D FEA. An example FEA result showing 3D flux lines is presented in Fig. 2. A non-overlapping concentrated winding is used for its shorter end turns and lower copper mass. The shorter end turns are particularly beneficial in case of axial flux machines which generally have larger diameters compared to machines with radial air-gaps. A double layer winding is utilized in order to reduce the coil width and achieve a larger active diameter compared to the single layer windings.

Employing a more vigorous cooling system for any electric machine increases torque density. It is important to enhance the heat extraction in parts that most of the losses occur or the parts that are prone to more damage due to temperature rise. Copper losses are commonly a significant loss component and hence cooling of the stator compartments becomes vital.

One of the advantages of AFPM machines is the inherent self-ventilation and heat extraction due to their disc-shape rotor structure. While single sided AFPM machines can be cooled with a natural air or fan system [21], [22], stronger liquid cooling is commonly used in combination with the YASA machine [4], [7], [23], [24]. In the case of the YASA machine, the stator is sandwiched between two rotors and therefore the heat dissipation area may be less than that of a single stator 


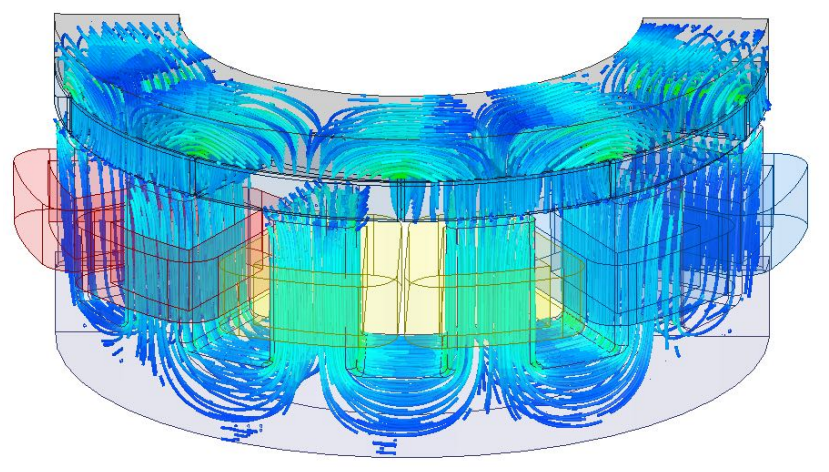

Fig. 2. The 3D FEA result, showing flux lines of the single sided AFPM machine (S2M).

\section{AFPM structure.}

Different implementations of cooling systems for the YASA machine have been proposed, some examples include the use of fins that are in direct contact with stator winding [25]-[27], forced liquid flowing in chambers [28] or coolant medium evaporating while passing through the sleeves [29] located in inner and outer diameter, or between the coils [30]. An additional note regarding cooling the YASA machine is in case of using epoxy for holding the stator segments which would require a high thermal conductivity [7], [25]. The performance of the machines under study in this paper are evaluated electromagnetically while thermal properties are assumed to be the same.

\section{Analytical Evaluation}

The electromagnetic torque of an AFPM machine with a pure q-axis current excitation, i.e. $i_{d}=0$, can be estimated from

$$
T_{e}=\frac{3}{2} \frac{p}{2} \lambda_{d} i_{q} ; \quad \lambda_{d}=\lambda_{m o}-L_{e} \cdot i_{q}
$$

where $p$ is the number of poles; $\lambda_{d}$, the d-axis flux linkage; $\lambda_{m o}$, the open circuit flux produced by the magnets; and $L_{e}$ is an equivalent inductance to capture the drop in d-axis flux linkage due to the q-axis current [31]. Figure 3 plots $\lambda_{d}$ versus $i_{q}$. It can be seen that this drop is fairly linear and the slope can be represented as an incremental inductance $L_{e}$

$$
L_{e}=\frac{\Delta \lambda_{d}}{\Delta i_{q}} .
$$

which has larger values for machines with higher magnetic saturation, as shown in Figs. 4a and 4b, resulting in a sharper decline in the d-axis flux under load operation. This results in non-linear torque-current characteristics, which will be further discussed.

The magnet flux, $\lambda_{m o}$, can be estimated as [32]

$$
\lambda_{m o}=\frac{2}{\pi} k_{w 1} N_{t} k_{v g} \alpha_{i} B_{g o} \tau_{p} L_{F e} ; B_{g o}=\frac{B_{r}}{\frac{1}{k_{\sigma}}+\frac{\mu_{m r} k_{c} k_{s o} g}{L_{p m}}},
$$

where $k_{w 1}$ is the fundamental winding factor; $N_{t}$, the number of turns per phase; $k_{v g}$, the ratio between the amplitude of the

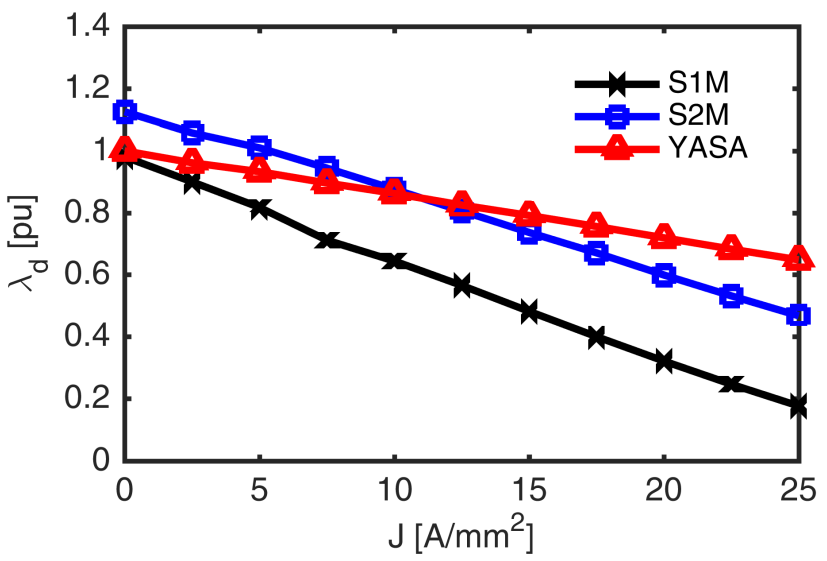

Fig. 3. D-axis flux linkage at different q-axis currents, per-unitized based on $\lambda_{d}$ of the YASA machine at open-circuit. The reduction in $\lambda_{d}$ due to $i_{q}$ is considerably higher for the single sided machines due to greater saturation.

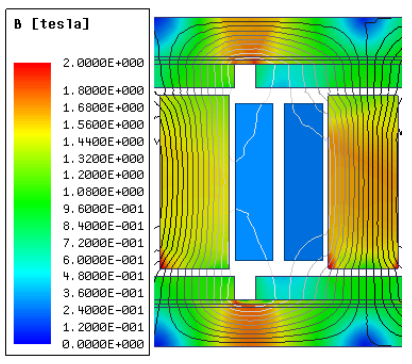

(a)

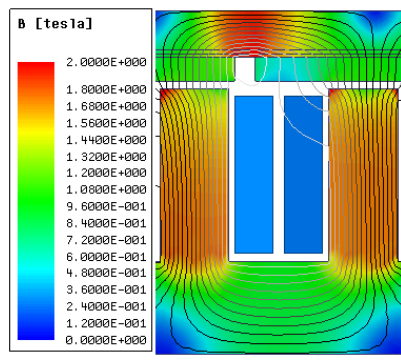

(b)
Fig. 4. Flux density distribution with pure q-axis excitation for (a) the YASA machine, and (b) the S1M machine, at the current density of $25 \mathrm{~A} / \mathrm{mm}^{2}$. The stator teeth and rotor core operate in saturation, which explains the reduction in d-axis flux at high q-axis currents."

fundamental wave and the average value of the air-gap flux density; $B_{g o}$, the peak value of the open-circuit flux density; $\tau_{p}$, the pole pitch; $L_{F e}$, the inner diameter subtracted from the outer diameter in case of an axial air-gap machine; $B_{r}$, the remanence of the magnets; $L_{p m}$, the magnet thickness in the direction of magnetization; $\alpha_{i}$, the pole-arc to pole-pitch ratio; $g$, the air-gap length; $k_{c}$, Carter's coefficient; $\mu_{m r}$, the relative permeability of the PM; $k_{s o}$, the d-axis saturation factor in the open-circuit operation; and $k_{\sigma}$ is the leakage coefficient.

Based on (3), for an unsaturated machine with negligible leakage and fringing $\left(k_{\sigma}, k_{c}\right.$, and $\left.k_{s o}=1\right), \lambda_{m o}$ is proportional to the ratio of the total magnet thickness to the total electromagnetic air-gap, i.e. $\frac{L_{p m}}{\mu_{m r} \cdot g+L_{p m}}$. The S1M machine has half the air-gap and half the magnet thickness of the YASA machine, while the S2M machine has half the mechanical air-gap of the YASA for the same overall magnet thickness. Therefore, $\frac{L_{p m}}{\mu_{m r} \cdot g+L_{p m}}$ is identical for S1M and YASA, while it is higher for S2M. This leads to a higher $\lambda_{m o}$ for S2M and comparable values for YASA and S1M, as observed in Fig. 3 $\left(\lambda_{d}\right.$ at $\left.i_{q}=0\right)$.

Another phenomenon affecting torque production, particularly at higher currents, is the armature reaction which strongly 
influences the displacement power factor. The displacement power factor is defined as the phase shift between the fundamental voltage and current, without taking the harmonics into account. The stator inductance, $L_{s}\left(L_{q}=L_{d}=L_{s}\right)$, may be estimated by

$$
L_{s}=\frac{m \mu_{0}\left(k_{w 1} N_{t}\right)^{2} \tau_{p} L_{F e}}{\pi^{2} p\left(k_{c} g+\frac{L_{p m}}{\mu_{m r}}\right)} \cdot \frac{1}{k_{s d}},
$$

where $m$ is the number of phases, and $k_{s d}$ the saturation coefficient with values larger than 1 for higher saturation levels. A larger electromagnetic air-gap results in a lower inductance, and thus a smaller armature reaction and a higher power factor. Therefore, the armature reaction effect would be lowest in case of the YASA machine and highest for the S1M. This is to the YASA's advantage, particularly at higher loadings.

A common argument is that the eliminated stator yoke in the YASA machine provides extra space for the stator and copper, resulting in a higher torque within the same volume. Nevertheless, not all of this space can be used by copper since some room must be provided for the second rotor disc. However, such an argument may be more credible in cases where the stator employs a thicker yoke for mechanical and/or electromagnetic reasons.

The torque production principles can also be explained with shear stress and the air-gap surface area [1]. The electromagnetic torque of any electric machine can be defined as the product of the electromagnetic force, $F$, and the radius:

$$
T_{e}=F r ; F=\sigma a_{a} ; \sigma=B A,
$$

where $r$ is the radius; $\sigma$, the electromagnetic air-gap shear stress; $a_{a}$, the air-gap area; $B$, the magnetic loading; and $A$, the electric loading defined as the ampere-turns per unit of periphery. Although in the YASA configuration $a_{a}$ is twice that of the single sided AFPM machine, $A$ and consequently $\sigma$ for each air-gap is reduced by half. Therefore, doubling the air-gap surface area in the YASA structure does not double the torque.

\section{DESIgN of EXPERIMENTS AND SENSITIVITY ANALYSIS}

The primary intent of the sensitivity analysis in this case is to study the impact of the loadings on the performance indices. To perform a systematic study, the performance indices (responses) and their corresponding variables (factors) are selected. Then, several designs are selected employing the design of experiments methodology. These designs, which best represent the relation between the responses and factors, are studied with 3D FEA evaluations. The sensitivity analysis is executed by a fitting a regression polynomial function. The factors with very small coefficients can be regarded as noise and their effect is neglected.

The responses selected are the electromagnetic torque, the stator core losses, and the displacement power factor. For each response, 7 variables are selected, including: the current density, $J$; the stator yoke to the total axial length ratio, $k_{s y}$;

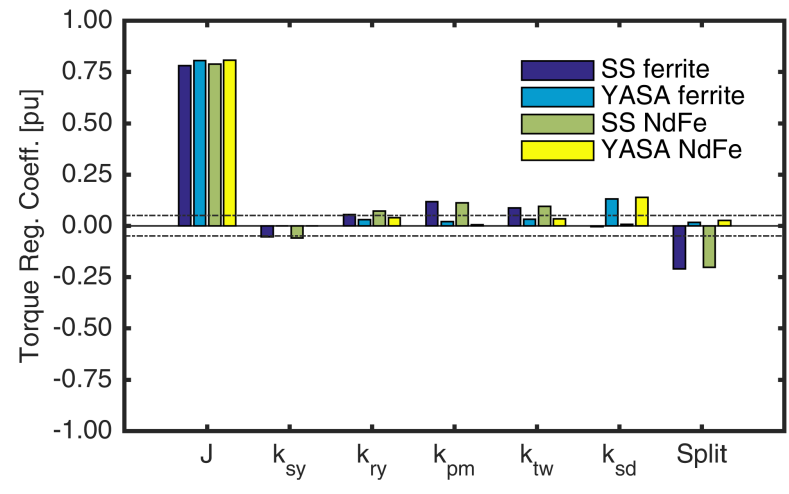

(a)

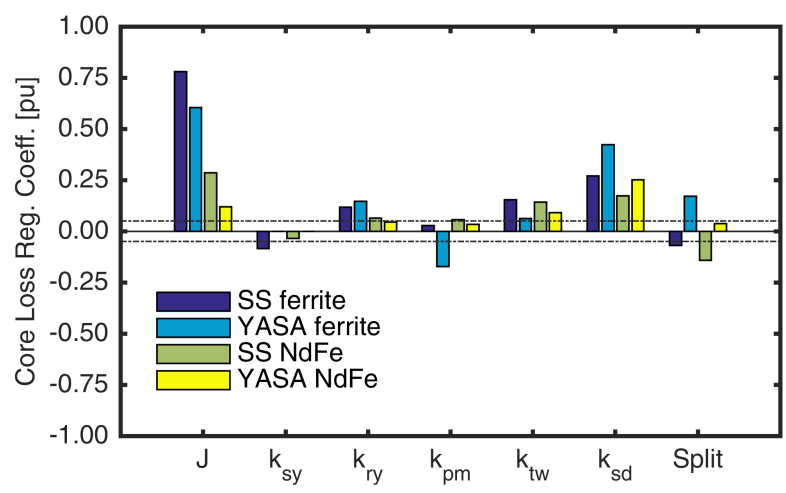

(b)

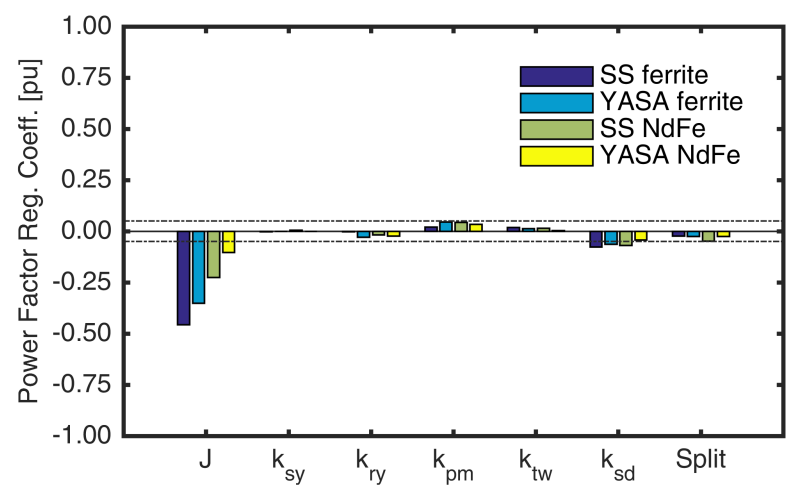

(c)

Fig. 5. The sensitivity analysis of the (a) electromagnetic torque, (b) stator core loss, and (c) power factor for single sided and YASA topologies. The horizontal dashed lines distinguish the insignificant factors with maximum effect being less than $5 \%$ variation in the response, within the studied range.

the rotor yoke to the total axial length ratio, $k_{r y}$; the magnet thickness to the total axial length ratio, $k_{p m}$; the slot depth to the total axial length ratio, $k_{s d}$; and the split ratio defined as the inner to the outer diameter ratio. Figure 5 represents the results, where positive values indicate a proportional increase in the response when the factor is increased, while negative values represent a proportional decrease. Larger values indicate a stronger sensitivity. 
TABLE I

THE PERFORMANCE OF THE YASA, S1M, AND S2M TOPOLOGIES PRODUCING EQUAL TORQUE AT THE SAME SPEED WITH FERRITE AND NDFE MAGNETS. THE POWER LOSS COMPONENTS ARE PER-UNITIZED BASED ON THE TOTAL LOSSES OF THE S2M MACHINE WITH NDFE MAGNETS.

\begin{tabular}{ll|rrr|rrr}
\hline & & \multicolumn{3}{|c}{ ferrite magnets } & \multicolumn{3}{c}{ NdFe magnets } \\
& & YASA & S1M & S2M & YASA & S1M & S2M \\
\hline Torque constant & {$[\mathrm{Nm} / \mathrm{A}]$} & 0.30 & 0.27 & 0.32 & 0.89 & 0.83 & 0.94 \\
Current density & {$\left[\mathrm{A} / \mathrm{mm}^{2}\right.$ ] } & 14.7 & 16.6 & 14.0 & 5.0 & 5.3 & 4.7 \\
Total stator core loss & [p.u.] & 0.07 & 0.30 & 0.24 & 0.20 & 0.26 & 0.30 \\
Stator yoke core loss & [p.u.] & 0.00 & 0.09 & 0.08 & 0.00 & 0.06 & 0.08 \\
Stator teeth core loss & [p.u.] & 0.07 & 0.22 & 0.16 & 0.20 & 0.20 & 0.23 \\
DC copper loss & [p.u.] & 5.09 & 6.42 & 4.57 & 0.53 & 0.67 & 0.51 \\
Additional ac copper loss & [p.u.] & 0.02 & 0.00 & 0.00 & 0.16 & 0.03 & 0.05 \\
Magnet loss & [p.u.] & 0.00 & 0.00 & 0.00 & 0.31 & 0.16 & 0.14 \\
Total loss & [p.u.] & 5.18 & 6.72 & 4.81 & 1.20 & 1.11 & 1.00 \\
Goodness & [Nm/ $\sqrt{W}$ ] & 0.16 & 0.14 & 0.16 & 0.32 & 0.34 & 0.36 \\
Power factor & & 0.97 & 0.83 & 1.00 & 0.98 & 0.99 & 1.00 \\
\hline
\end{tabular}

The study is conducted for machines with both ferrite and Neodymium magnets. The total magnet volume of each machine is identical in all cases. Some considerable outcomes of the sensitivity analysis, demonstrated in Fig. 5, are as follows:

1) An increase in the ampere-turns improves the electromagnetic torque more significantly in the YASA compared to the single sided machine, which is due to to the YASA's lower armature reaction.

2) The stator and rotor yoke thicknesses have negligible effects, indicating that the yokes are not saturated within the studied range.

3) In case of an increased slot depth, the improvement in torque production is considerable only in the YASA machine. This can be attributed to the increased flux leakage in the single sided machines with deeper slots.

4) Due to the larger volume of the stator core in the single sided machines and the larger armature reaction, the effect of the current on core loss is higher.

5) The reduction in the displacement power factor due to the increased current density is more significant for the single sided machine. This is due to smaller armature reaction of the YASA machine.

6) Higher magnetic loading causes less reduction in the displacement power factor at overload operation. This is in line with expectations, due to the smaller per unit reactance with $\mathrm{NdFeB}$ magnets than with ferrites.

\section{Performance Comparison at Typical Loadings}

The performance of the three topologies at typical current density values with both ferrite and $\mathrm{NdFeB}$ magnets has been investigated in this section. Based on analytical evaluations, it is expected that for such current density levels, with identical winding layout and currents, the machines with a higher ratio of the overall magnet thickness to the effective air-gap, have a higher specific torque. This means for the YASA machine to have the lowest torque and S2M the highest. For current density of $5 \mathrm{~A} / \mathrm{mm}^{2}$ the under study YASA, S1M, and S2M machines with ferrite magnet have torque constants of 0.23 , 0.25 , and $0.30 \mathrm{Nm} / A$, respectively. The same machines with
$\mathrm{NdFe}$ magnets represent torque constants of $0.60,0.66$, and $0.77 \mathrm{Nm} / \mathrm{A}$, respectively. Thus, the FEA results are in line with analytical predictions.

In order to evaluate in more detail at comparable operating points, the armature current of the three machines under study are adjusted to give the same torque. The performance details are summarized in Table I. The current density required to produce the same torque is lower in case of the S2M machine.

The stators are made of SMC material. Therefore, the stator core loss comprises mainly hysteresis losses. The eliminated stator yoke significantly reduces core losses of the YASA machine. Utilizing ferrite magnets the stator core loss of S1M is greater than S2M, while with $\mathrm{NdFe}$ magnets $\mathrm{S} 2 \mathrm{M}$ has a higher stator loss. Stator core losses result from the variation in flux density of both magnets and armature windings. Although the designs with $\mathrm{NdFe}$ magnets have larger air-gap flux density, they require lower current for the same toque. The reduced current lowers the core loss caused by armature field and the stronger magnet increases the core losses generated by excitation field. The stator yoke and teeth loss components are separated to show that majority of the core loss is in the teeth. The rotor back iron loss is negligible for these case studies.

The additional ac copper loss is caused by eddy current induced due to magnets passing over the stator. The conductors placed closer to the slot opening are exposed to the leakage flux and are responsible for the majority of the ac winding losses. As the slot depths are identical for the three machines, for the same number of turns, the YASA machine is expected to have a higher winding eddy current loss due to double the exposure from the slot opening on both ends of the stator and also small gap between top layer of conductors and the magnets. The copper losses for designs with rare earth magnet are shown in Fig. 6. The p.u. magnitude of these losses, in the case of the single sided machines with the ferrite magnets are very small. Employing rare earth magnets as shown in Table I, the YASA machine has winding eddy current losses about four times the S2M. This becomes a more significant disadvantage at high speed applications. 


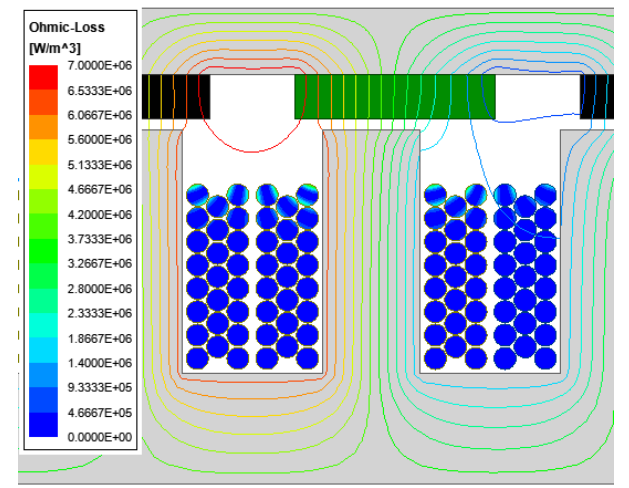

(a)

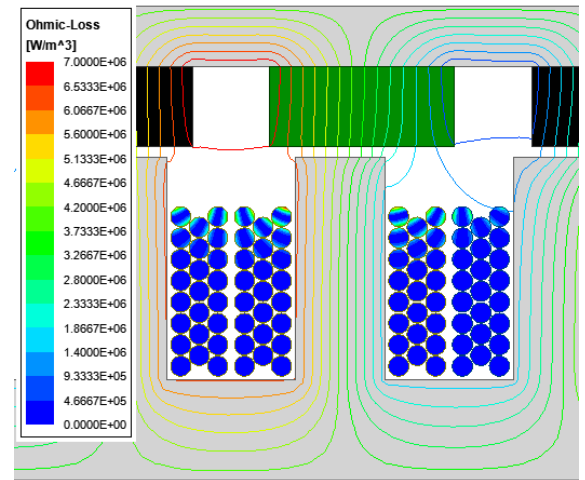

(b)

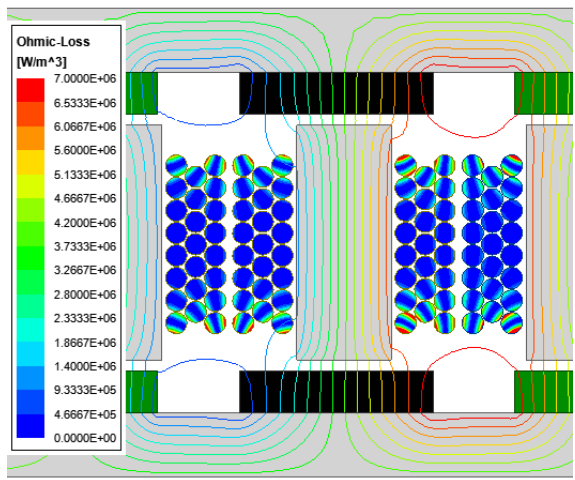

(c)

Fig. 6. Ac copper losses together with the flux lines of the designs with rare earth magnets for the (a) S1M, (b) S2M, and (c) YASA machine. Note that the color scales are identical.

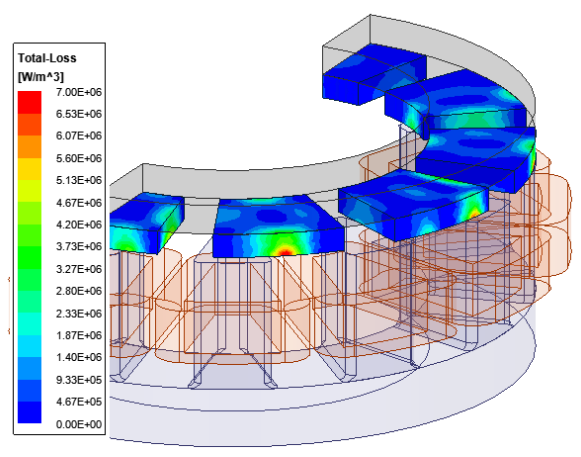

(a)

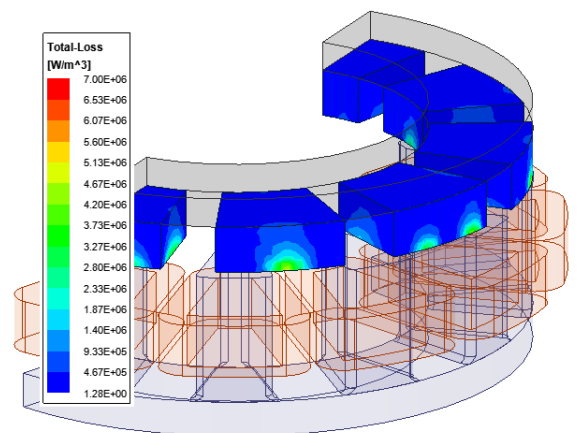

(b)

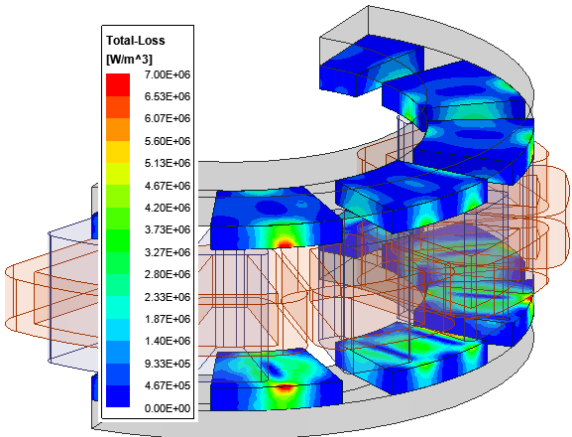

(c)

Fig. 7. Magnet losses and the flux lines of the designs with rare earth magnets for the (a) S1M, (b) S2M, and (c) YASA machine. Note that the color scales are identical.

The magnet losses are also calculated using FEA, shown in Fig. 7. The majority of losses happen on the surfaces of the magnet pieces closer to the air-gap that are more exposed to the variations of the flux density. This is more significant for the YASA machine with double the air-gap area. Thus the magnet losses of the YASA machine is higher as noted in Table I.

The goodness values, defined as $\frac{\text { Torque }}{\sqrt{\text { Losses }}}$, are close to each other, indicating that none of the designs perform considerably higher than the rest. The power factor for the S1M design is the lowest, a result which is in line with expectations due to the high per unit inductance. When using ferrite magnets, the power factor of S2M is slightly superior to that of the YASA machine due to higher back EMF. Based on analytical evaluation and the results form Fig. 5c, it is expected that the power factor reduction with stronger magnets for the YASA machine is less steep, resulting in better performance compared to the S2M design.

The mechanical losses are not included in the Table I. The bearing loss is estimated to be lower than the other loss components. The bearing loss of the single sided machine is expected to be double that of the YASA machine due to the increased axial load, consequently requiring larger bearings.

\section{OVERLOAD CAPABILITY}

The torque production and loss of the machines are evaluated at higher magnetic and electric loadings using 3D FEAs. In previous section it was shown that at lower loadings, the torque constant is the highest for S2M, followed by S1M, and then the YASA. In this section, it is found that at higher loadings, the situation changes, Figs. 8 and 9.

Figure $8 \mathrm{a}$ and $8 \mathrm{~b}$ represent the torque at different currents with ferrite and rare earth magnets. The torque produced by S1M at higher currents declines very quickly due to its lower magnetic lower and also higher saturation particularly at very high loads. S2M remains slightly better than YASA for a wider range until YASA produces more torque, at very high loadings.

The torque-ampere turn characteristics of the single sided machine, start to bend at smaller currents as compared with the YASA. This may be an indication of the higher cross coupling saturation of single sided machine. Therefore, the d-axis flux linkage declines more, shown in Fig. 3. The lower saturation of the YASA machine can be seen from the flux density distribution plots in Fig. 10. 


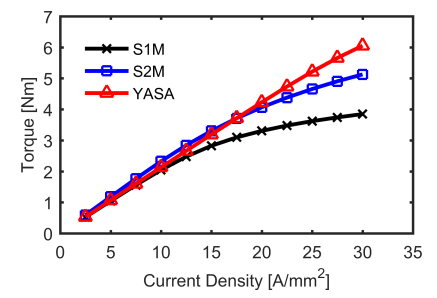

(a)

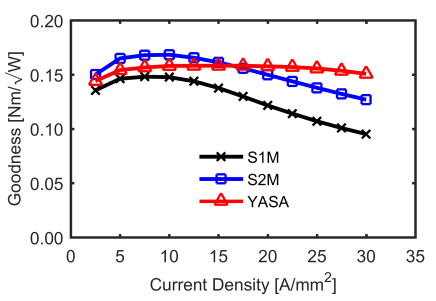

(c)

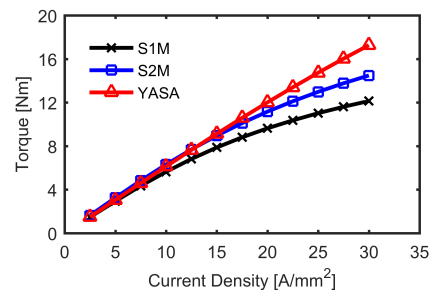

(b)

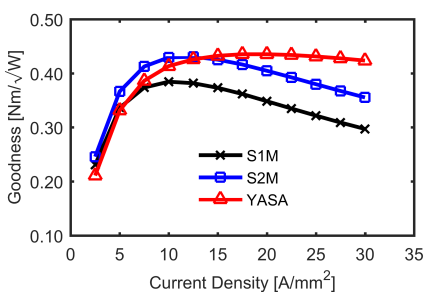

(d)

Fig. 8. The torque production of YASA, S1M and S2M topologies with slot depth of $\mathcal{L}$. (a) electromagnetic torque with ferrite magnets, and (b) with Neodymium magnets, (c) goodness with ferrite magnets, and (d) with Neodymium magnets.

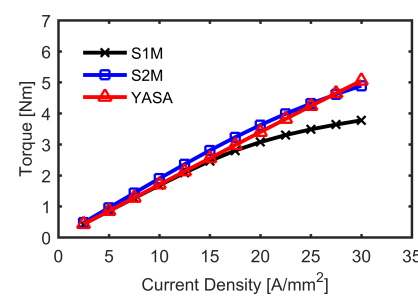

(a)

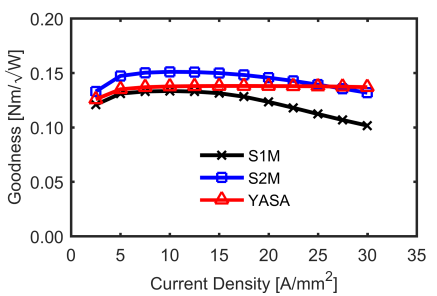

(c)

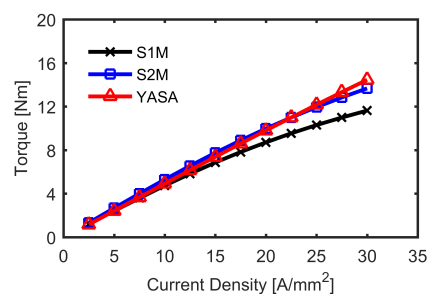

(b)

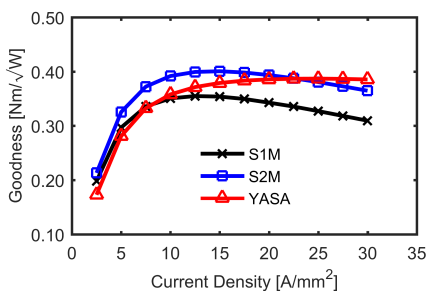

(d)
Fig. 9. The torque production of YASA, S1M and S2M topologies with $20 \%$ slot depth reduction compared to Fig. 8 , i.e., $0.8 \cdot \mathcal{L}$. (a) electromagnetic torque with ferrite magnets, and (b) with Neodymium magnets, (c) goodness with ferrite magnets, and (d) with Neodymium magnets.

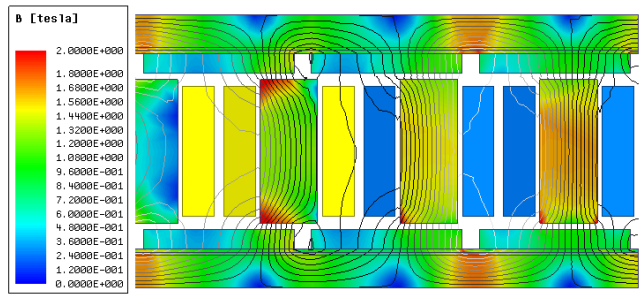

(a)

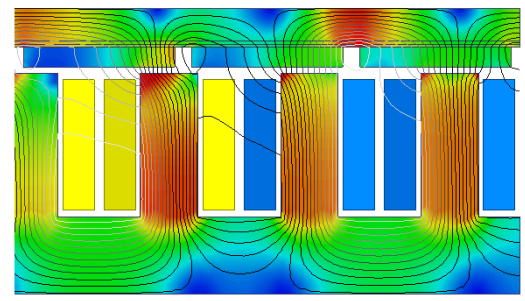

(b)

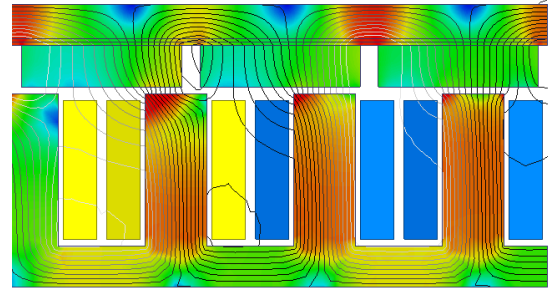

(c)

Fig. 10. Flux density distribution and flux lines at high magnetic and electric loading, current density of $25 \mathrm{~A} / \mathrm{mm}^{2}$ with Neodymium magnets, of the (a) YASA, (b) S1M, and (c) S2M machines.

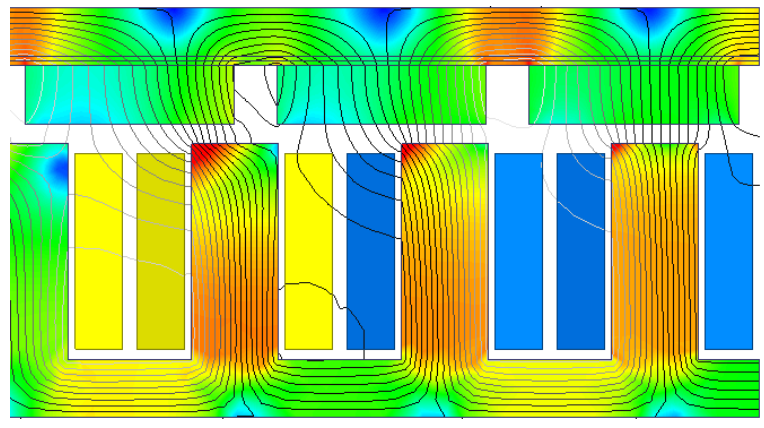

Fig. 11. The flux density and lines for a design, $S 2 M_{a g}$, obtained by doubling the air-gap length of the S2M design employing NdFeB magnets.

One argument could be that the saturation effects can be reduced by increasing the air-gap length or increasing the back iron thickness. In order to address this, a possible fourth design, $\mathrm{S}_{2} \mathrm{M}_{2 a g}$ with twice the length of the mechanical airgap of the S2M machine, was investigated and results pre-

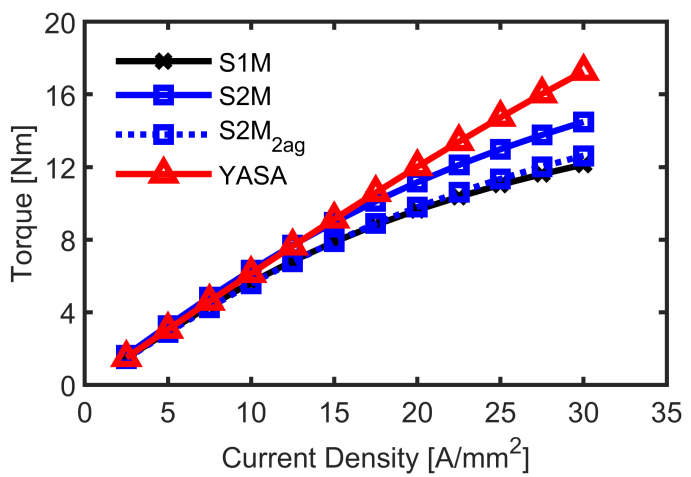

Fig. 12. The torque production capabilities of the design, $S 2 M_{a g}$, from Fig. V plotted comparatively with machines of different topologies employing $\mathrm{NdFeB}$ magnets.

sented in Figs. 12 and V. In line with expectations, the larger air-gap increases leakage and fringing and reduces armature reaction effect resulting in marginally lower flux density in 
TABLE II

THE EXPERIMENTAL VALIDATION OF 3D FEA MODELS FOR BACK EMF CONSTANT [V/RAD.S]. ALL MACHINES EMPLOY NDFE MAGNETS.

\begin{tabular}{lrr}
\hline & \multicolumn{2}{c}{ Back EMF Constant } \\
& 3D FEA & Measurement \\
\hline YASA & 0.28 & 0.29 \\
S1M & 0.27 & 0.29 \\
S2M & 0.32 & 0.34 \\
\hline
\end{tabular}

the magnetic circuit and hence potential reduced core losses for the same current loading. Nevertheless, the larger air-gap causes a reduction in the torque constant, which will require a higher current in order to compensate for the torque output.

The sensitivity analysis from the previous section indicated that back iron thickness does not significantly influence the performance of the machines under study in this paper. Another systematic approach consists of optimally designing machines for a given specification, in which case the values for each of the geometrical variables, including air-gap and back iron, may be different for each of the topologies considered. Such a systematic comparative study was recently reported by the authors in another conference paper, showing that the superiority of a machine topology depends on output specification and cooling capabilities [20].

The single sided machines have a higher stator core loss due to higher saturation and volume of the stator core. In order to include losses in the comparison, goodness defined as $\frac{\text { Torque }}{\sqrt{\text { Losses }}}$ is plotted, Fig. 8c and 8d. The goodness of the single sided topologies at higher loads declines more significantly as compared with the YASA.

Based on the sensitivity analysis in Fig. 5a, increased slot area in the axial direction (slot depth, $k_{s d}$ ) enhances torque production of the YASA topology more significantly than the single sided. This may be due to the flux leakage that is likely to impact the single sided machines more than the YASA. The increased slot depth leads to more slot area and current. On the other hand, it also increases the flux leakage particularly in case of the single sided structures, which impedes further torque production. This is not the case for the YASA machine. Therefore, it is expected that YASA outperforms single sided structure at even lower current densities when more space is permitted in the axial direction. Likewise, for axially shorter designs single sided machines outperform YASA machine in a wider range of current density. This is shown by a second study for a smaller frame with $20 \%$ reduction in the slot depth, Fig. 9, where the YASA structure only barely outperforms the single sided machine at very high current densities.

\section{EXPERIMENTAL VALIDATION}

The 3D FEA model is validated with experimental measurements for the single sided and YASA machine. The prototyped machines are shown in Fig. 13. The test setup for the YASA and single sided machine are shown in Fig. 14. Measurements are performed in order to test the comparative performance of the machines under study at different electric loadings, in
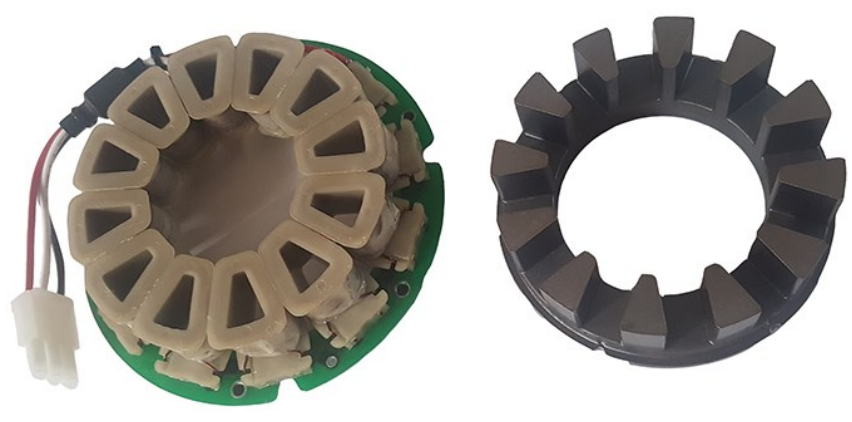

(a)
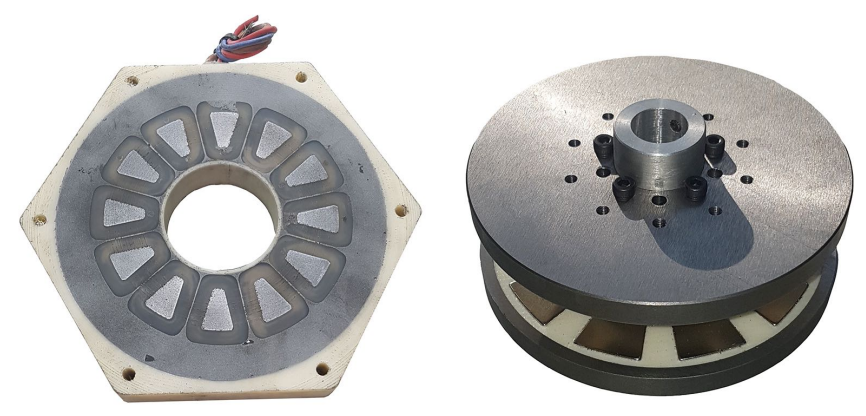

(b)

Fig. 13. (a) Dissembled stator, coils (left) and core (right), of the single sided machines. The same stator is used for S1M and S2M prototype machines. (b) The YASA machine, segmented stator (left) and both rotors (right), employed for experimental validation of the study. Similar rotors are used for single sided machines, with magnet thickness of only one of the rotors in the YASA machine (S1M) and double that thickness (S2M).

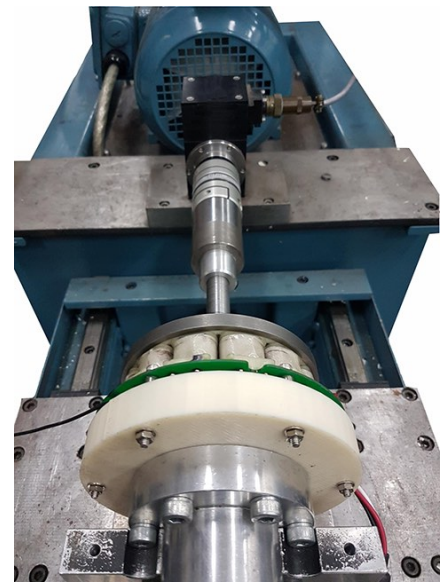

(a)

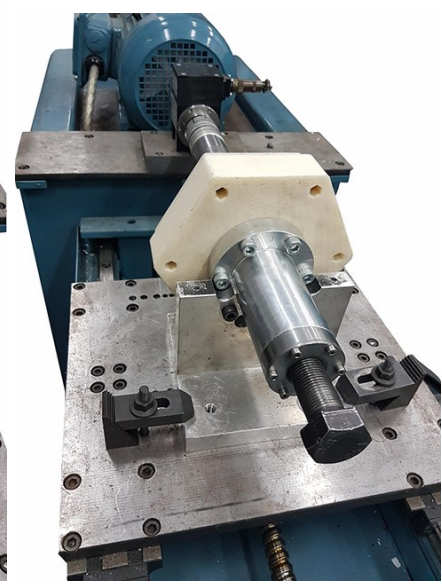

(b)
Fig. 14. Test setup of the (a) single sided and (b) YASA machines under study.

addition to validate the FEA results. The favorable agreement between back EMF constant obtained from measurements and 3D FEA, presented in Table II, attest to the fidelity of the simulations.

The measurement of the torque-current characteristics are obtained for all three machines ensuring identical temperature by allowing sufficient cooling time between each measure- 




Fig. 15. The measured and 3D FEA calculated torque-current characteristics.

ment. The YASA machine presents a higher torque only at high load operational conditions, as tested and presented in Fig. 15, which also verifies that the results are in agreement with 3D FEA calculations.

\section{CONCLUSION}

The performance of the YASA machine compared to single sided machines at different loadings is comprehensively examined. The armature reaction, saturation effects, loss components, power factor, and torque constant are among the performance indices which are studied. The sharper decline in the d-axis flux and higher cross-coupling saturation for single sided machine compared to the YASA machine is analytically and numerically discussed. It is shown that at typical electric loads the torque production capability of single sided machine is higher than the YASA machine with similar total magnet volume. The eddy current copper loss and magnet loss of the YASA machine is also higher. Therefore, it may be said that for the machines under study and for naturally cooled low to medium speed applications, the performance of the single sided machine is better than that of the YASA topology. On the other hand, for applications requiring a high torque density, which employ forced cooling, the YASA machine may have advantages. It is illustrated that the YASA structure is more suitable where more space for slots in axial direction is available. The results obtained from 3D FEA calculations are confirmed experimentally. The studies indicate that the choice of AFPM machine configuration is heavily dependent on application requirements, the ratings and dimensional specifications.

\section{ACKNOWLEDGMENT}

The support of Regal Beloit Corporation, University of Kentucky, the L. Stanley Pigman endowment and the SPARK program, and ANSYS Inc. is gratefully acknowledged.

\section{REFERENCES}

[1] M. Rosu, P. Zhou, D. Lin, D. M. Ionel, M. Popescu, F. Blaabjerg, V. Rallabandi, and D. Staton, Multiphysics Simulation by Design for Electrical Machines, Power Electronics and Drives. Wiley-IEEE Press, 2017.
[2] C. C. Chan, "Axial-field electrical machines design and applications," IEEE Transactions on Energy Conversion, vol. EC-2, no. 2, pp. 294300, June 1987.

[3] T. J. Woolmer and M. D. McCulloch, "Analysis of the yokeless and segmented armature machine," in 2007 IEEE International Electric Machines Drives Conference, vol. 1, May 2007, pp. 704-708.

[4] B. Zhang, Y. Wang, M. Doppelbauer, and M. Gregor, "Mechanical construction and analysis of an axial flux segmented armature torus machine," in 2014 International Conference on Electrical Machines (ICEM), Sep. 2014, pp. 1293-1299.

[5] W. Fei, P. C. K. Luk, and K. Jinupun, "A new axial flux permanent magnet segmented-armature-torus machine for in-wheel direct drive applications," in 2008 IEEE Power Electronics Specialists Conference, June 2008, pp. 2197-2202.

[6] P. Sergeant, H. Vansompel, and L. Dupre, "Performance and implementation issues considering the use of thin laminated steel sheets in segmented armature axial-flux pm machines," in 2014 International Conference on Electrical Machines (ICEM), Sept 2014, pp. 1363-1369.

[7] B. Zhang, T. Seidler, R. Dierken, and M. Doppelbauer, "Development of a yokeless and segmented armature axial flux machine," IEEE Transactions on Industrial Electronics, vol. 63, no. 4, pp. 2062-2071, April 2016.

[8] A. D. Gerlando, G. M. Foglia, M. F. Iacchetti, and R. Perini, "Parasitic currents in stray paths of some topologies of yasa afpm machines: Trend with machine size," IEEE Transactions on Industrial Electronics, vol. 63, no. 5, pp. 2746-2756, May 2016.

[9] D. Moreels and P. Leijnen, "White paper: High efficiency axial flux machines," MAGNAX, Tech. Rep. V1.7, May 2018. [Online]. Available: www.magnax.com

[10] S. T. Vun and M. D. McCulloch, "Optimal design method for largescale yasa machines," IEEE Transactions on Energy Conversion, vol. 30 , no. 3, pp. 900-907, Sep. 2015.

[11] B. Zhang, T. Epskamp, M. Doppelbauer, and M. Gregor, "A comparison of the transverse, axial and radial flux pm synchronous motors for electric vehicle," in 2014 IEEE International Electric Vehicle Conference (IEVC), Dec 2014, pp. 1-6.

[12] N. J. Stannard, J. G. Washington, and G. J. Atkinson, "A comparison of axial field topologies employing smc for traction applications," in 2016 19th International Conference on Electrical Machines and Systems (ICEMS), Nov 2016, pp. 1-6.

[13] T. Husain, B. Tekgun, Y. Sozer, and M. Hamdan, "Comparison of axial flux machine performance with different rotor and stator configurations," in 2017 IEEE International Electric Machines and Drives Conference (IEMDC), May 2017, pp. 1-8.

[14] M. F. Khatab, Z. Zhu, H. Li, and Y. Liu, "Comparative study of axial flux magnetically geared machine with conventional axial flux yasa machine." in 2018 IEEE International Magnetics Conference (INTERMAG), April 2018, pp. 1-1.

[15] R. Di Stefano and F. Marignetti, "A comparison between soft magnetic cores for axial flux pm synchronous machines," in 2012 XXth International Conference on Electrical Machines, Sep. 2012, pp. 1922-1927.

[16] F. Marignetti, V. D. Colli, and S. Carbone, "Comparison of axial flux pm synchronous machines with different rotor back cores," IEEE Transactions on Magnetics, vol. 46, no. 2, pp. 598-601, Feb 2010.

[17] Syed Qurban Ali Shah and I. Hahn, "Comparative analysis of surface mounted and flux focusing type axial flux permanent magnet motor," in 8th IET International Conference on Power Electronics, Machines and Drives (PEMD 2016), April 2016, pp. 1-4.

[18] G. De Donato, F. Giulii Capponi, G. A. Rivellini, and F. Caricchi, "Integral-slot versus fractional-slot concentrated-winding axial-flux permanent-magnet machines: Comparative design, fea, and experimental tests," IEEE Transactions on Industry Applications, vol. 48, no. 5, pp. 1487-1495, Sep. 2012.

[19] N. Taran, G. Heins, V. Rallabandi, D. Patterson, and D. M. Ionel, "Torque production capability of axial flux machines with single and double rotor configurations," in 2018 IEEE Energy Conversion Congress and Exposition (ECCE), Sep. 2018, pp. 7336-7341.

[20] N. Taran, G. Heins, V. Rallabandi, D. Patterson, and D. M. Ionel, "Systematic comparison of two axial flux pm machine topologies: Yokeless and segmented armature versus single sided," in 2019 IEEE Energy Conversion Congress and Exposition (ECCE), Sep. 2019, pp. 4477-4482. 
[21] M. Polikarpova, P. Ponomarev, P. Lindh, I. Petrov, W. Jara, V. Naumanen, J. A. Tapia, and J. Pyrhönen, "Hybrid cooling method of axial-flux permanent-magnet machines for vehicle applications," IEEE Transactions on Industrial Electronics, vol. 62, no. 12, pp. 7382-7390, Dec 2015.

[22] L. Yu, X. Zhao, D. Wang, and X. Bao, "Losses calculation and ventilation cooling of air-cooled axial-flux permanent magnet asynchronous couplings," in 2018 Chinese Control And Decision Conference (CCDC), June 2018, pp. 5053-5058.

[23] R. Camilleri, T. Woolmer, A. Court, and M. D. McCulloch, "Investigation into the temperature profile of a liquid cooled yasa(c) afpm machine," in 6th IET International Conference on Power Electronics, Machines and Drives (PEMD 2012), March 2012, pp. 1-8.

[24] R. Camilleri, D. A. Howey, and M. D. McCulloch, "Predicting the temperature and flow distribution in a direct oil-cooled electrical machine with segmented stator," IEEE Transactions on Industrial Electronics, vol. 63, no. 1, pp. 82-91, Jan 2016.

[25] H. Vansompel, A. Hemeida, and P. Sergeant, "Stator heat extraction system for axial flux yokeless and segmented armature machines," in 2017 IEEE International Electric Machines and Drives Conference (IEMDC), May 2017, pp. 1-7.

[26] A. H. Mohamed, A. Hemeida, H. Vansompel, and P. Sergeant,
"Parametric studies for combined convective and conductive heat transfer for yasa axial flux permanent magnet synchronous machines,' Energies, vol. 11, no. 11, 2018. [Online]. Available: https://www.mdpi. com/1996-1073/11/11/2983

[27] D. Winterborne, N. Stannard, L. Sjöberg, and G. Atkinson, "An aircooled yasa motor for in-wheel electric vehicle applications," in 2019 IEEE International Electric Machines Drives Conference (IEMDC), May 2019, pp. 976-981.

[28] T. Woolmer, "Electric machine-flux," Patent, U.S. Patent 9071117B2, Jun. 30, 2015.

[29] T. Woolmer, "Electric machine-evaporative cooling," Patent, U.S. Patent 8581455B2, Nov. 12, 2013.

[30] T. Woolmer, "Machine cooling systems," Patent, U.S. Patent 2017/0012480A1 , Jan. 12, 2017.

[31] D. M. Ionel, M. J. Balchin, J. F. Eastham, and E. Demeter, "Finite element analysis of brushless dc motors for flux weakening operation," IEEE Transactions on Magnetics, vol. 32, no. 5, pp. 5040-5042, Sep 1996.

[32] N. Taran, V. Rallabandi, D. M. Ionel, and G. Heins, "Coreless and conventional axial flux permanent magnet motors for solar cars," IEEE Transactions on Industry Applications, vol. 54, 2018, Accepted for publication. 